\title{
Association of financial or professional conflict of interest to research outcomes on health risks or nutritional assessment studies of genetically modified products
}

\author{
Johan Diels ${ }^{a}$, Mario Cunha ${ }^{b}$, Célia Manaia ${ }^{a}$, Bernardo Sabugosa-Madeira ${ }^{c}$, Margarida Silva ${ }^{a, *}$ \\ ${ }^{a}$ CBQF/Escola Superior de Biotecnologia da Universidade Católica Portuguesa, Rua Dr. António Bernardino de Almeida, 4200-072 Porto, Portugal \\ ${ }^{\mathrm{b}}$ Faculdade de Ciências da Universidade do Porto, Dep. Geociências, Ambiente e Ordenamento do Território and Centro de Investigação de Ciências Geoespaciais, \\ Rua do Campo Alegre, s/n, 4169-007 Porto, Portugal \\ ${ }^{\mathrm{c}}$ Escola Superior Agrária de Ponte de Lima, IPVC. 4990-706 Ponte de Lima, Portugal. ENVISED - Grupo de Ambiente, \\ Sociedade e Educação do Centro de Geologia da Universidade do Porto. Rua do Campo Alegre, s/n, 4169-007 Porto, Portugal
}

Keywords:

Conflict of interest

Health risk

Nutritional value

Genetically modified plants

GMOs

\begin{abstract}
A B S T R A C T
Since the first commercial cultivation of genetically modified crops in 1994, the rapidly expanding market of genetically modified seeds has given rise to a multibillion dollar industry. This fast growth, fueled by high expectations towards this new commercial technology and shareholder trust in the involved industry, has provided strong incentives for further research and development of new genetically modified plant varieties. Considering, however, the high financial stakes involved, concerns are raised over the influence that conflicts of interest may place upon articles published in peer-reviewed journals that report on health risks or nutritional value of genetically modified food products. In a study involving 94 articles selected through objective criteria, it was found that the existence of either financial or professional conflict of interest was associated to study outcomes that cast genetically modified products in a favorable light $(p=0.005)$. While financial conflict of interest alone did not correlate with research results $(p=0.631)$, a strong association was found between author affiliation to industry (professional conflict of interest) and study outcome $(p<0.001)$. We discuss these results by comparing them to similar studies on conflicts of interest in other areas, such as biomedical sciences, and hypothesize on dynamics that may help explain such connections.
\end{abstract}

\section{Introduction}

The research and development of genetically modified organisms (GMOs) in agriculture is a relatively recent field in applied biotechnology research, as the first commercial sowing of a genetically modified (GM) crop took place as recently as 1994 . However, worldwide GM crop acreage has been expanding mostly at two digit speed totaling 134 million hectares in 2009 (James, 2009), turning genetic engineering into a global industry worth $\$ 10.5$ billion in the same year and expected to grow over an estimated $\$ 11$ billion by 2011 (James, 2009). So far the majority of GM crops have been destined for the production of animal feed, but food products (such as vegetable oils), textiles and biofuels are also common end products (GMO Compass, 2008). Despite such clear successes GM crops have also been plagued by consumer rejection, especially in the European Union (Gaskell et al., 2006).

In its 2008 annual report, Monsanto, the current main global seller of GM seeds (Lotter, 2008a), stated that this resistance and

\footnotetext{
* Corresponding author. Tel.: +351 225580057.

E-mail address: msilva@esb.ucp.pt (M. Silva).
}

low market acceptance is a current risk factor that can undermine profit rates (Monsanto Company, 2008). While the discourse of opponents to GM crops in scientific and public communities extend over a whole range of environmental (Benbrook, 2009; Lövei and Arpaia, 2005), socioeconomic (Hubbard, 2009), health (Domingo, 2007; Then and Potthof, 2009) and ethical arguments (Jensen and Sandoe, 2002), many of these critical discourses converge at the point where the role of science in assessing risks and impacts is being discussed (Levidow et al., 2005; Myhr and Traavik, 2003).

In recent years, research institutions have become increasingly dependent on private funding (Etzkowitz, 2005; Welsh and Glenna, 2007). According to Lotter (2008b) this trend has oriented science towards a new direction where 'university research is harnessed to promote the emergence of a knowledge economy'. It is a model where some see science as having become 'embedded in commercial possibility' (Slaughter and Leslie, 1997). This observed close relationship between scientific research and industry has led to concerns over the possible influence of financial conflicts of interests (COIs) in the design and outcomes of studies investigating human and animal health risks or nutritional value of GM products (Lotter, 2008b; Myhr and Traavik, 2003). Considering the controversy that 
surrounds GMOs, studies are closely watched on both sides. On one hand, studies showing absence of health risks or demonstrating nutritional equivalence serve to justify commercialization by companies and authorizations by decision-makers. On the other hand, studies indicating health or environmental risks have been used by environmental NGOs to criticize positions favorable to GMO (Friends of the Earth, 2005; Sample, 2010).

Over the last decades COIs have regularly been the subject of lively debate within the scientific community. Especially in connection with biomedical sciences, scientists (Kassirer, 2009; Krimsky and Rothenberg, 1998; Resnik, 2009), journalists (Van Kolfschooten, 2002) and journal editors (Drazen and Curfman, 2002; Smith, 1998) have raised concerns over the integrity of industry supported research and the need for full disclosure of such information to readers of scientific articles.

Over time, associations have repeatedly been observed between study outcomes favoring the industry's point of view and industry sponsorship, suggesting a publication bias generated through the presence of COIs (Ahmer et al., 2005; Als-Nielsen, 2003; Bekelman et al., 2003; Bhandari et al., 2004; Kjaergard and Als-Nielsen, 2002; Lexchin et al., 2003). The influence of entanglements of scientists with industry has also been revealed in other research areas. Examples include studies on the health effects of smoking (Diethelm et al., 2005; Muggli et al., 2003) and research in nutritional sciences (Lesser et al., 2007).

The hypothesis of this study is that there exists no relation between COI and study outcome. Or in other words, COI does not imply actual behavior. But COI does represent an arguable risk that may draw scientists away from objective study design and observation (Horton, 1997; Lo, 2009; Smith, 1994). The main question in this study is whether COIs, through direct industry funding (financial COI) or through professional affiliations (professional COI), exert a detectable influence on study outcome for articles that report on health risks and nutritional value of GM crop derived foods. Currently no systematized data is available that would provide clear insights into a topic which has been the subject of a highly polarized debate for several years.

\section{Methodology}

The methodology used is from Lesser et al. (2007), a study that investigated financial COIs within nutrition research, adapted to the GM topic in terms of article inclusion criteria and expanded to include professional affiliations. These changes justify a full length description of the methodology.

Through a set of objective criteria, a sample of articles was generated. Two independent co-investigators classified the conclusions of each article as generally "favorable", "unfavorable" or "neutral". A third independent co-investigator classified for each article sponsorship, author affiliation and COI. None of the coinvestigators had any prior knowledge of the classification produced by their peers and had access only to the article sections relevant to their task. Finally, the relationship between conclusion type and sponsors was tested through the application of appropriate statistical methods.

\section{Article selection}

Articles were initially selected through a series of searches in the Medline ${ }^{\circledR}$ (National Library of Medicine, US) and Web of Science ${ }^{\circledR}$ (ISI Web of Knowledge, Thomson Scientific) bibliographic databases. Key terms were selected based on commonly used article keywords within the scientific literature. Search terms were composed based on combinations of three key terms. The total number of search strings was defined by the total amount of pos- sible combinations between the items of three categories of key terms related to: 'effects' (14 key terms), 'terminology' (three key terms) and 'product purpose' (two key terms). The first category contained the following key terms: 'toxicity', 'health effects', 'adverse effects', 'toxic effects', 'dietary effects', 'biological effects', 'safety', 'safety assessment', 'safety risks', 'evaluation of safety', 'health safety', 'nutritional value', 'effect of feeding', and 'feeding value'. The second category included 'GM', 'genetically modified' and 'transgenic'. The third category contained the key terms 'food' and 'feed'. Examples of search strings are 'health effects of GM food', or 'nutritive value of genetically modified feed'. All possible combinations totaled 84 search strings. Each search string was applied to both the Medline and Web of Science databases, resulting in 168 searches. Afterwards an automatic filter produced a list of all references occurring in any of the outcome listings.

Articles were further selected through manual review of title and abstract by applying the following criteria:

- The topic of the article relates to a GM plant as a food or feed product or as an ingredient of a food or feed product.

- The study involved or considered consumption of the GMO product by animals or humans with the intention of measuring a biological response or involved data collection on participants or from an uncontrolled or natural environment without the intervention of the investigator.

- At least one endpoint relates directly to health, disease, or a disease marker in animals or humans or to the nutritional value of the GMO product under research.

- The article was published between January 1980 and February 2009 (inclusive).

- The article was written in English.

The following step consisted in collecting the full text of the articles. In those cases where it was not available on the Internet or through the Portuguese Catholic University's full text on line library services, the lead author was contacted. If there was no response or the request was denied, the article was excluded.

One co-investigator received a document with article extracts containing only the funding source declaration for each article, author affiliations and the name of the GMO product under study. Two other co-investigators had the parallel task of confirming the inclusion of articles based on the initial selection criteria and classifying each article's conclusions according to outcome based on the abstract, the discussion and conclusion sections of each article.

\section{Classification by funding source and author affiliation}

The co-investigator applied his own knowledge or generally available information on the Internet, to characterize each sponsor as

- Industry - including corporations or organizations that represent corporations.

- Industry associated - including organizations or government agencies that work with industry to promote consumption of specific foods or the use of specific feeds.

- Non-industry - including governmental agencies with no industry associations, universities, and independent foundations, philanthropies, and other non-profit organizations.

- Unknown - if information about the sponsor could not be retrieved.

And classified the affiliation of each author as:

- Academic - including affiliations to universities.

- Non-governmental - including affiliations to independent foundations, philanthropies, and other non-profit organizations. 
- Governmental - including affiliations to government agencies or structures.

- Industry - including affiliations to corporations or organizations tied to corporations.

- Unknown - if the author's affiliation could not be identified.

Overall funding source could then be classified for each article as

- All industry - if all financial sponsors were classified as industry.

- No industry - if all financial sponsors were classified as nonindustry.

- Mixed - if any financial sponsor was classified as industry associated, or if the article had financial sponsors that were classified into more than one category including at least one sponsor classified as industry.

- Unknown - If all financial sponsors were classified as unknown.

- Undeclared - If no financial sponsors were declared in the article.

And the author affiliation was further characterized as:

- Affiliation with industry - when at least one of the authors is affiliated with industry.

- No affiliation with industry - when none of the authors are affiliated with industry.

- Undetermined - when not all author affiliations could be identified and the ones identified are not industry affiliated.

The relationship between sponsor or authors and the product under investigation was characterized by the co-investigator as follows:

- Professional COI - if a positive finding appears to be in the commercial interest of a company to which at least one of the authors is affiliated.

- Funding COI - if a positive finding appears to be in the commercial interest of at least one sponsor classified as industry.

Financing from industry associated entities was not included in this classification because they represent a heterogeneous category of where it is difficult to determine the real weight of industry funding.

Combining the information obtained through previous classifications, each article could be classified as:

- COI - if COI through sponsorship or author affiliation is present.

- Undetermined - if financial sponsorship was classified as undeclared or unknown while no professional COI was identified, or if minimum one author affiliation was classified as unknown while no financial conflict was identified.

- No COI - if none of the authors in the article was affiliated to an entity with a commercial interest in the product under investigation and no sponsors had such commercial interest.

\section{Classification by conclusion type}

Articles were divided between those in which the conclusions were favorable to the interests of the GMO patent holder, and those that were unfavorable. A third, neutral category was foreseen to include articles where the outcome was inconclusive.

Articles were classified on the basis both of the general tone of the author's discourse and formal conclusions. Acknowledging that a classification partially based on the tone of discourse does leave room for subjective interpretation, two co-investigators with different backgrounds were co-opted to carry out the same task independently and as such help neutralize any interference personal bias may bring into the classification.
Each article was classified based on the following criteria:

1. Favorable - If the co-investigator finds that no statement were made that cast the product in a negative light and, at the same time, the conclusions suggest one or more of the following:

(a) Beneficial health effects.

(b) Increased nutritional value.

(c) Absence of adverse health effects.

(d) Equivalence in nutritional value between the GM product and the non-GM reference line, if the GM product was not developed with the aim to increase nutritional value.

2. Unfavorable - If the co-investigator finds that no statements were made that cast the product in a positive light and, at the same time the conclusions suggest one or more of the following:

(a) Absence of expected beneficial health effects.

(b) Adverse health effects.

(c) Lower nutritional value of the GM product when compared to the non-GM reference line.

(d) Equal nutritional value of the GM product, when compared to the non-GM reference line, if the GM product was developed with the aim to increase nutritional value.

3. Neutral - If the co-investigator finds the study is inconclusive or criteria for a favorable or unfavorable classification were not met.

Finally, the two co-investigators exchanged classification data An article was excluded if no consensus was reached on assigned categories.

\section{Statistical analysis}

The Fisher Exact Test was applied in order to test the associations between funding source, author affiliation and conclusion type (Zar, 1998). This statistical significance test is based on a contingency table in which the observed behavior in a specific situation is compared with a hypothetical distribution in which no COI is observed (null hypothesis). $P$-values were calculated as the sum of the exact $p$-value of the observed distribution and any distribution more extreme than the one observed. The 5\% $(p<0.05)$ probability level was the threshold used for statistical significance.

Since this research focuses on contrasts between favorable versus unfavorable studies as regards the GM product under study, the neutral category articles were left out of the analysis. A conservative approach also led to the exclusion of the 'mixed' funding class, as it represents a heterogeneous group of studies where it is difficult to differentiate between industry and other funding sources. Finally, articles where either the presence or absence of a COI could not be confirmed were also excluded (articles classified as undetermined).

\section{Results}

Searches in the Medline and Web of Science databases resulted in 3626 unique references (after having filtered out duplicates). All 3626 references could be found in a specific minimum combination of 51 search strings. The remaining 117 searches only produced duplicates.

Through the manual review of abstract and the title, 120 articles were selected. Of all but four articles the full text could be retrieved through the university library. One author did not respond to our request, two others could not be reached and the fourth study proved only to be an abstract of a poster presentation by the author. Furthermore, 12 full texts were not in English, which reduced the total number of articles to 104 . After co-investigator 
review, six more articles were left out based on the consensus that they did not respond to the initial selection criteria. Another four articles were left out of the statistical analysis as a consensus could not be reached regarding their conclusion classification. This resulted in a sample of 94 articles accepted for statistical analysis.

Figs. 1 and 2 present detailed information on this sample. In Fig. 1, the distribution of articles according to publication year shows that, although inclusion of articles from 1980 onwards was allowed, no articles were detected before 1996. Fig. 2 provides information regarding the nature of the included studies. It shows that the sample had a close to equal representation of studies investigating GMO products destined for either food or feed (38 and 36), with a smaller proportion of studies considering products for both human or animal consumption (20). As for distribution of study objectives, 23 studies contain data on nutritional value, 43

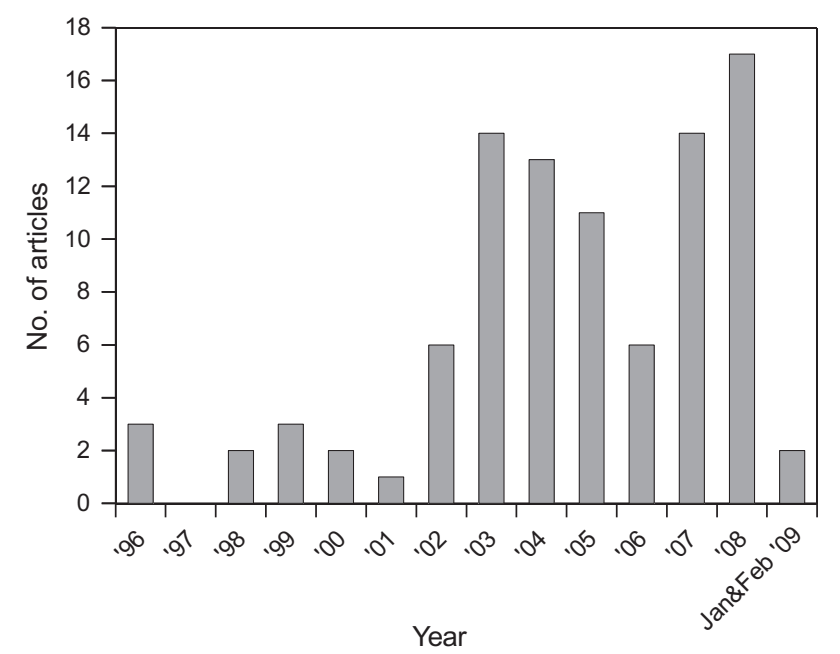

Fig. 1. Publication year of articles $(n=94)$. No articles published before 1996 were present in the population. Only articles published until the end of February 2009 were included. on health risks and a smaller group of 28 studies combined conclusions on both nutritional value and health risks. Finally, Fig. 2 shows that a majority of studies were interventional studies (66), meaning that they considered GM product consumption by animals or humans with the intention of measuring a biological response. There were 28 studies on compositional analysis or simulations.

The classification of the articles based on the co-investigator analysis is presented in Table 1 . From the 94 articles selected, 80 (85\%) were identified as containing a favorable outcome, 12 (13\%) were classified as unfavorable and two (2\%) as neutral. Funding was declared in 45 articles (48\%). Thirty-six studies (38\%) received funding from non-industry related sources, two (2\%) from mixed sources and seven ( $8 \%$ ) from industry or industry related sources. Out of these seven articles, six were classified as containing a financial COI.

As regards affiliation, in 41 articles (44\%), at least one of the study authors was connected with industry, while no such

Table 1

Classification of articles by the co-investigators $(n=94)$. F: Favorable; U: Unfavorable; $\mathrm{N}$ : Neutral.

\begin{tabular}{llrrrr}
\hline & & F & U & N & Total \\
\hline All articles & - & 80 & 12 & 2 & 94 \\
Funding source & All industry & 6 & 1 & 0 & 7 \\
& No industry & 26 & 8 & 2 & 36 \\
& Mixed & 2 & 0 & 0 & 2 \\
& Unknown & 0 & 0 & 0 & 0 \\
& Undeclared & 46 & 3 & 0 & 49 \\
Financial conflict of interest & & 5 & 1 & 0 & 6 \\
Author affiliation to industry & Yes & 41 & 0 & 0 & 41 \\
& No & 39 & 12 & 2 & 53 \\
Professional conflict of interest & Unknown & 0 & 0 & 0 & 0 \\
Conflict of interest (financial and/or & - & 41 & 0 & 0 & 41 \\
professional) & Yes & 43 & 1 & 0 & 44 \\
& & & & & \\
& No & 27 & 8 & 2 & 37 \\
& Undetermined & 10 & 3 & 0 & 13 \\
\hline
\end{tabular}

A

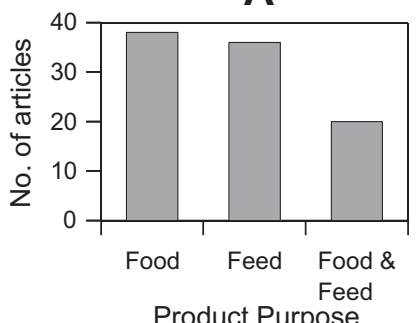

Product Purpose
B

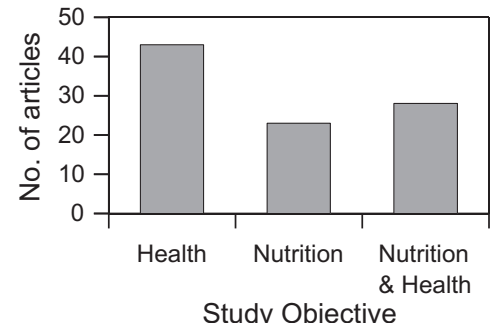

C

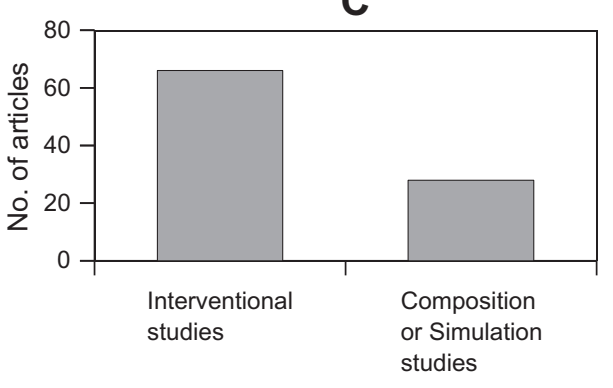

Study Type

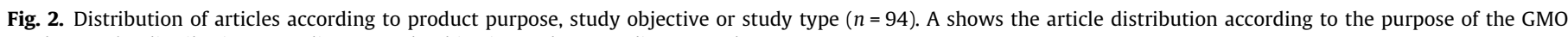
product, $\mathrm{B}$ the distribution according to study objective and $\mathrm{C}$ according to study type. 
Table 2

Relation between article conclusion and conflict of interest. Exact $p$ is the statistical significance of the Fischer Exact Test. In the analysis of COI, only those articles were included where certainty could be obtained that a COI was either present or absent.

\begin{tabular}{llll}
\hline Conflict of interest (COI) & \multicolumn{2}{l}{ Conclusion } & \multirow{2}{*}{ Exact $p$} \\
\cline { 2 - 3 } & Favorable & Unfavorable & \\
\hline Financial COI & 5 & 1 & 0.631 \\
Yes & 29 & 8 & \\
No & & & \\
Professional COI & 41 & 0 & $<0.001$ \\
Yes & 39 & 12 & 0.005 \\
No & & & \\
COI (financial and/or professional) & 43 & 1 & 0.036 \\
Yes & 27 & 8 & \\
No & & & \\
Declaration of funding & 34 & 9 & \\
Declared & 46 & 3 & \\
Undeclared & & & \\
\hline
\end{tabular}

Table 3

Relation between author affiliation and article declaration of funding or funding source. Exact $p$ is the statistical significance of the Fischer Exact Test.

\begin{tabular}{|c|c|c|c|}
\hline \multirow[t]{2}{*}{ Article funding } & \multicolumn{2}{|c|}{ At least one another of industry } & \multirow[t]{2}{*}{ Exact $p$} \\
\hline & Yes & No & \\
\hline \multicolumn{4}{|c|}{ Declaration of funding } \\
\hline Declared & 7 & 36 & $<0.001$ \\
\hline undeclared & 36 & 13 & \\
\hline \multicolumn{4}{|l|}{ Funding source } \\
\hline All industry & 5 & 2 & $<0.001$ \\
\hline No industry & 2 & 34 & \\
\hline
\end{tabular}

affiliation was attributed to any of the remaining articles. For all these articles a COI was identified through author affiliation to the industry with a vested commercial interest in the product under research. Combining all information it was possible to determine that, globally, 44 articles, or $47 \%$, contained either a financial or professional COI or both. In 37 articles (39\%) no COI was detected, whereas in 13 cases (14\%) it could not be determined with certainty whether a COI was in fact absent or went undetected due to lack of information available on financial sponsorship or author affiliation.

Regarding financial COI, no association was observed between the presence of such conflict and article outcome $(p=0.631)$ (Table 2). A relationship was found between absence of declaration of funding and a favorable outcome $(p=0.036)$ (Table 2$)$. Furthermore, there was a strong connection between undeclared funding and the presence of one or more authors affiliated to industry $(p<0.001)$ (Table 3). Author affiliation to industry was also strongly related to funding received from an industry source $(p<0.001)$ (Table 3$)$. Professional COI was significantly related with article conclusion $(p<0.001)$ (Table 2$)$. Finally, a joint analysis of both data on funding and professional COI revealed that the presence of $\mathrm{COI}$ was significantly related to favorable outcome $(p=0.005)$ (Table 2).

\section{Discussion}

The main finding of our study is that, based on the dataset available, articles where a COI was identified show a tendency to produce outcomes favorable to the associated commercial interests. These results support the overall view that all affiliations should be clearly acknowledged in scientific publications on the risk analysis of GM food or feed products, as the existence of such conflicts of interest is somehow interfering with study outcomes. Due to a lack of comparable studies in the genetic engineering area, the present discussion reflects instead upon publications with similar approaches conducted for other scientific subjects.

Despite this overall significant result, the data used did not show a connection between funding source and article outcome. This seems to contradict a range of evidence demonstrating the influence that financial conflicts of interest have in other science areas, especially in biomedical (Lo, 2009) but also in nutritional sciences (Lesser et al., 2007). However, since funding information was scant, most of the articles had to be excluded from this specific analysis which could have affected its statistical power. It must be noted that articles without declaration of funding tend to relate to a favorable outcome, meaning this category does not represent a neutral group of articles even though it was conservatively excluded from the analysis.

On the other hand, a strong relationship was found between favorable outcome and professional COI. Krimsky et al. (1996) had already documented the widespread presence of professional COIs among university based authors through patent ownership, a function within or holding shares of a biotechnology company. Within the nutritional sciences Nestle (2007) commented that relations through financial sponsorship and project partnerships between academics and industry are rather the rule than the exception. While professional entanglements with industry or personal commercial interests and possible publication bias have in general been researched less than influence of direct funding, the existence of an influence of such relations has been observed in biomedical sciences by Friedman and Richter (2004). Also, in 2001, several editors of main medical journals expressed their concerns over industry relations which included professional affiliations. In particular they showed strong opposition against "contractual agreements that deny investigators the right to examine the data independently or to submit a manuscript for publication without first obtaining the consent of the sponsor" (Davidoff et al., 2001). While medical journals have over the years been implementing a number of changes in their disclosure policies to better deal with COIs (Smith, 1998), recent work still shows the issues have yet to be solved satisfactorily (Jagsi et al., 2009; Lo, 2009; Wingate, 2009).

An echo of the above cited editorial sounded in a news feature in Nature in October 2009, where contractual agreements, publication restrictions and other dependencies that disturb scientific integrity were presented as common practice in research on risks analysis of GM plants (Waltz, 2009). In fact, would-be independent researchers of GM plants' potential impacts are even more restricted to carry out their research because of technology agreements that effectively allow a company to prohibit any research on their product without its explicit authorization even after it has been approved and marketed. In comparison, patents of pharmaceutical products do not reach that far in the sense that they do not prevent any investigation on their performance or impact.

It should be emphasized that, according to the present results, articles where at least one of the authors is affiliated to industry are strongly linked to absence of funding declaration. In fact, out of 41 articles where an industry affiliated author was present, only seven declared funding. The ratio is opposite in the cases where no author was observed to be affiliated to industry. Considering that in all those 41 articles a professional conflict was observed explains why the majority of articles were included into the combined analysis of professional and funding COI. In this analysis only 15 articles were excluded as it could not be determined whether a financial COI was either absent or present even though no professional COI was observed (13) or they were classified as neutral (two).

Current data do not provide sufficient insight into the underlying dynamics that lead to this particular result, which renders 
interpretation speculative. One possibility is that studies with active industry participation choose to publish in journals where there are no strict requirements over funding disclosure in order not to reveal funding sources. Very few studies with declared funding received funding from industry only. Additionally, the absolute majority of studies with non-industry funding had no involvement of industry affiliated authors. However, it is unlikely that the proportion of non-industry versus industry funding is representative for research in GM crops, considering the high involvement of industry in biotechnology research (Lotter, 2008b).

Since the data available make no mention of contractual agreements or publication restrictions, other causes, as suggested by Lesser et al. (2007) may explain the observed association. Industry may tend to choose to be involved only in such research that is likely to cast their product in favorable light, or researchers, under certain conditions, may design studies and draw conclusions that respond to the financial interests of their industrial sponsors or employers.

Financial COIs are also not the only type of personal conflicts that researchers may face (Bekelman et al., 2003; Hirsch, 2009). Career considerations, long standing personal scientific viewpoints, or value-based opinions over the role of science in society and faith in technology as a useful tool for solving global problems, may influence author perceptions and study outcomes.

We recognize that similar dynamics may apply to researchers and studies funded by other sources than industry, such as government agencies or civil society organizations, since those entities may have a preference towards funding studies or researchers serving their political agendas. In the same line, Ravetz (2004) considers that modern science in general is set 'by the external interests that supply funds' and scientists are influenced by values. While interests and personal values are not the same, they may coincide. Kvakkestad et al. (2007) for example found that the perspectives of scientists in regard to the deliberate release of GMOs are related to the nature of their employer.

In order to further shed light on the influence of financial COIs it will be necessary to see how the data presented here associates with journal titles and their respective disclosure policies. Considering the high number of studies with no declared funding it should also prove useful to investigate financial sources. Finally, it will be interesting to also analyze environmental risk studies or to include risk analysis studies of other (non-GMO) food products, which would allow for a comparison between different types of studies.

\section{Conclusion}

The presence of $\mathrm{COI}$ in scientific research does not imply actual behavior of study authors. But it does present a risk that the study outcome may be improperly influenced. This study has focused on how commercial interests may interfere with outcomes of risk and nutrition analysis studies of products derived from GM plants. This is a choice justified by the high financial stakes involved in the development of such products and the increasing weight of private funding in research in recent years.

Through statistical analysis of a selected population of studies in the described area, it could be shown that a combined analysis of COIs through professional affiliations or direct research funding are likely to influence the final outcome of such studies in the commercial interest of the involved industry. Our results partially confirm those observed in biomedical sciences, tobacco, alcohol and nutrition research.

Various hypothesis could be identified that may explain the observed association between study outcome and presence of financial COI: publication restrictions imposed by industry funders; contractual agreements of authors with industry; industry bias favoring friendly research; and researchers that are sensitive to the financial interests of their industrial sponsors or employers.

Apart from the observed relations, it was considered that types of funding other than industry, such as governments and NGOs may also condition investigation. Additionally, values held by scientists may influence research outcomes as well.

Our data reinforce the need to that all affiliations whether financial or professional should be openly declared in scientific publications. In situations where health risk assessments or nutritional evaluation studies of GM products serve to inform decisionmakers, procedures could be developed to minimize the risk of decisions being taken based on study outcomes that have been influenced by conflicts of interest. This may best be achieved by giving preference towards peer-reviewed studies where no COI can be observed.

\section{Acknowledgement}

We would like to thank Dr. Helena Ribeiro for her helpful assistance in the statistical treatment of the data.

\section{References}

Ahmer, S., Arya, P., Anderson, D., Faruqui, R., 2005. Conflict of interest in psychiatry. Psychiatric Bulletin 29 (8), 302-304.

Als-Nielsen, B., 2003. Association of funding and conclusions in randomized drug trials: a reflection of treatment effect or adverse events? Journal of the American Medical Association 290 (7), 921-928.

Bekelman, J.E., Li, Y., Gross, C.P., 2003. Scope and impact of financial conflicts of interest in biomedical research a systematic review. Journal of the American Medical Association 289 (4), 454-465.

Benbrook, C., 2009, Impacts of Genetically Engineered Crops on Pesticide Use. The Organic Center. <http://www.organic-center.org/reportfiles/13Years20091126 FullReport.pdf> (accessed 06.06.10).

Bhandari, M., Busse, J.W., Jackowski, D., Montori, V.M., Schunemann, H., Sprague, S., et al., 2004. Association between industry funding and statistically significant pro-industry findings in medical and surgical randomized trials. Canadian Medical Association Journal 170 (4), 477-480.

James, C., 2009. Global status of Commercialized biotech/GM Crops. ISAAA. <http:// www.isaaa.org/Kc/Publications/pdfs/isaaabriefs/Briefs\%2032.pdf> (accessed 06. 06.10).

Davidoff, F., DeAngelis, C.D., Drazen, J.M., Hoey, J., Hojgaard, L., Horton, R., et al., 2001. Sponsorship, authorship, and accountability. The Journal of the American Medical Association 286 (10), 1232-1234.

Drazen, J.M., Curfman, G.D., 2002. Financial associations of authors. The New England journal of medicine 346 (24), 1901

Diethelm, P., Rielle, J., Mckee, M., 2005. The whole truth and nothing but the truth? The research that Philip Morris did not want you to see. The Lancet 366 (9479), 86-92.

Domingo, J., 2007. Toxicity studies of genetically modified plants: a review of the published literature. Critical Reviews in Food Science and Nutrition 47 (8), 721 733.

Etzkowitz, H., 2005. The rise of the entrepreneurial university. International Journal of Contemporary Sociology 42 (1), 28-43.

Friedman, L.S., Richter, E.D., 2004. Relationship between conflicts of interest and research results. Journal of General Internal Medicine 19 (1), 51-56.

Friends of the Earth, 2005. What's wrong with an EFSA opinion? <www. saveourseeds.org/downloads/FOE_1507_critique_2006.pdf> (accessed 06.06 . 10).

Gaskell, G., Allansdottir, A., Allum, N., Corchero C., Fischler C., et al., 2006. Europeans and Biotechnology in 2005: Patterns and Trends. Eurobarometer 64.3. <http:/ www.ec.europa.eu/research/press/2006/pdf/pr1906_eb_64_3_final_report-may 2006_en.pdf> (accessed 06.06.10).

GMO Compass, 2008. GM Crops The Big Four: Soybean, Maize, Rapeseed and Cotton. <http://www.gmo-compass.org/eng/grocery_shopping/crops> (accessed 12.01.10)

Hirsch, L.J., 2009. Conflicts of interest, authorship, and disclosures in industryrelated scientific publications: the tort bar and editorial oversight of medical journals. Mayo Clinic Proceedings 811, 821.

Horton, R., 1997. Conflicts of interest in clinical research: opprobrium or obsession? The Lancet 349 (9059), 1112-1113.

Hubbard, K., 2009. Farmers face the consequences of a consolidated seed industry The Farmer to Farmer Campaign. Retrieved from http://farmertofarmer campaign.com/Out\%20of\%20Hand.FullReport.pdf (accessed 06.06.10).

Jagsi, R., Sheets, N., Jankovic, A., Motomura, A.R., Amarnath, S., Ubel, P.A., 2009 Frequency, nature, effects, and correlates of conflicts of interest in published clinical cancer research. Cancer 115 (12), 2783-2791. 
Jensen, K.K., Sandoe, P., 2002. Food safety and ethics: the interplay between science and values. Journal of Agricultural and Environmental Ethics 15 (3), 245-253.

Kassirer, J.P., 2009. Commentary: disclosure's failings: what is the alternative? Academic Medicine: Journal of the Association of American Medical Colleges 84 (9), 1180-1181.

Kjaergard, L.L., Als-Nielsen, B., 2002. Association between competing interests and authors' conclusions: epidemiological study of randomised clinical trials published in the BMJ. British Medical Journal 325 (7358), 249.

Krimsky, S., Rothenberg, L.S., Stott, P., Kyle, G., 1996. Financial interests of authors in scientific journals: a pilot study of 14 publications. Science and Engineering Ethics 2 (4), 395-410.

Krimsky, S., Rothenberg, L.S., 1998. Financial interest and its disclosure in scientific publications. The Journal of the American Medical Association 280 (3), 225-226.

Kvakkestad, V., Gillund, F., Kjolberg, K.A., Vatn, A., 2007. Scientists perspectives on the deliberate release of GM crops. Environmental Values 16, 79-104.

Lesser, L.I., Ebbeling, C.B., Goozner, M., Wypji, D., Ludwig, D.S., 2007. Relationship between funding source and conclusion among nutrition-related scientific articles. PLoS Medicine 4 (1), 41.

Levidow, L., Carr, S., Wield, D., 2005. European Union regulation of agribiotechnology: precautionary links between science, expertise and policy. Science and Public Policy 32 (4), 261-276.

Lexchin, J., Bero, L.A., Djulbegovic, B., Clark, O., 2003. Pharmaceutical industry sponsorship and research outcome and quality: systematic review. British Medical Journal 326 (7400), 1167-1170.

Lo, B., Institute of Medicine (US), 2009. Conflict of interest in medical research, education, and practice. National Academies Press, Washington D.C.

Lotter, D., 2008a. The genetic engineering of food and the failure of science-part 1: the development of a flawed enterprise. International Journal of the Sociology of Agriculture and Food 16 (1), 31-49.

Lotter, D., 2008b. The genetic engineering of food and the failure of science - part 2 : academic capitalism and the loss of scientific integrity. International Journal of the Sociology of Agriculture and Food 16 (1), 50-68.

Lövei, G., Arpaia, S., 2005. The impact of transgenic plants on natural enemies: critical review of laboratory studies. Entomologia Experimentalis et applicata $114(1), 1-14$.
Monsanto Company, 2008. Annual Report. Retrieved from <http://www.monsanto. com/investors/financial_reports/annual_report/2008/default.asp> (accessed 06.06.10).

Muggli, M., Hurt, R., Blanke, D.D.B., 2003. Science for hire: a tobacco industry strategy to influence public opinion on secondhand smoke. Nicotine and Tobacco Research 5 (3), 303-314.

Myhr, A.I., Traavik, T., 2003. Genetically modified (GM) crops: precautionary science and conflicts of interests. Journal of agricultural and Environmental Ethics 16 (3), 227-247.

Nestle, M., 2007. Food company sponsorship of nutrition research and professional activities: a conflict of interest? Public Health Nutrition 4 (05), 1015-1022.

Ravetz, J., 2004. The post-normal science of precaution. Futures 36 (3), 347-357.

Resnik, D.B., 2009. Perspective: disclosing hidden sources of funding. Academic Medicine: Journal of the Association of American Medical Colleges 84 (9), 12261228

Sample, I., 2010. Scientists call for GM review after surge in pests around cotton farms in China. The Guardian, 13 May. <http://www.guardian.co.uk/ environment/2010/may/13/gm-crops-pests-cotton-china> (accessed 06.06.10).

Slaughter, S., Leslie, L.L., 1997. Academic Capitalism: Politics, Johns Hopkins University Press, Policies, and the Entrepreneurial University. Baltimore, MD.

Smith, R., 1994. Conflict of interest and the BMJ. British Medical Journal 308 (6920), 4-5.

Smith, R., 1998. Beyond conflict of interest. British Medical Journal 317 (7154), 291296.

Then, C., Potthof, C., 2009. Risk Reloaded - Risk analysis of genetically engineered plants within the European Union. Testbiotech e.V. <www.testbiotech.org/sites/ default/files/risk-reloaded_engl.pdf > (accessed 06.01.10).

Van Kolfschooten, F., 2002. Conflicts of interest: can you believe what you read? Nature 416 (6879), 360-363.

Waltz, E., 2009. Under wraps. Nature Biotechnology 27 (10), 880-882.

Welsh, R., Glenna, L., 2007. Considering the role of the university in conducting research on agri biotechnologies. Social Studies of Science 36 (6), 929-942.

Wingate, S., 2009. Professional associations and conflict of interest. Heart and Lung: The Journal of Acute and Critical Care 38 (4), 283.

Zar, J.H., 1998. Biostatistical Analysis. Hall International, London, UK. 